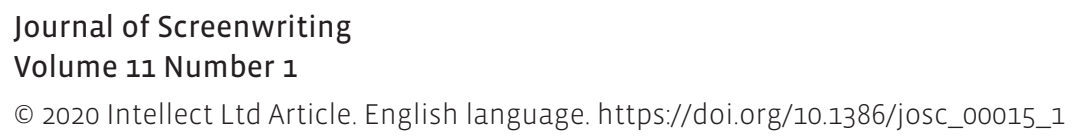

\title{
Negotiating autobiographical truth: Embodying sensation in the narrative screenplay
}

\section{ABSTRACT}

This article examines how screenwriting adaptations of written material speak of levels of truth-telling within various autobiographical texts. These include literary adaptations by Marguerite Duras: Hiroshima Mon Amour (1959) and The North China Lover (1992), and the autobiographical filmmaking of Maya Deren: Meshes of the Afternoon (1946) and The Very Eye of Night (1958). I argue that descriptions of tactile sensation necessarily remain codified in screenplays, their connotations left hanging even when the filmmaking process often falls short of depicting final truth. What remains is an unresolved problematic perception standing in for an experience. Our own experience of cinema can invariably be one wherein neither words nor images appear, or reappear, as to how they felt for the screenwriter. Is this a wholly negative situation, or merely the continuation of mediation, remediation and the contingent transposition of one medium into another? Drawing on examples from the screenwriting and/or filmmaking of Duras and Deren, I discuss why the screenwriter always writes in personal terms (because the personal is inescapable), and that this is a personal experience of imagination through the writing. Moreover, I test the idea that screenwriting only emerges in a form that we can recognize as truth, through its depictions of tactility and its representations of sensation.

\section{KEYWORDS}

Duras

Deren

adaptation mediation autobiography embodiment sensation 
Screenwriting often reveals and withholds in more or less equal measures. It is a form of codified text, which uses language to withhold aspects of the visual images to come. What writing for the screen reveals are intentions, suggested actions (both physical and intellectual), the writer's hopes, guidelines and instructions, while it also attempts to withhold much about the persona of the writer. This article will do several things, central among which is to interrogate notions of autobiographical truth(s) that are revealed by writing that, in some capacity, forms the practice of screenwriting. Underpinning the autobiographical expressivity that is utilized by Marguerite Duras and Maya Deren, I argue that images of tactile sensation (Barker 2009) appear intrinsic to their narrative concerns yet necessarily remain codified in their writing for film, there in the imagination of the reader but with a finality of their connotations left hanging until qualities of tactility are resolved through the filmmaking process.

A central question the article thus poses is whether screenwriting necessarily or inevitably falls short of depicting final truth (Mecke 2007) through its literary representations of female experiences of physical sensation or if it depicts some other quality of autobiographical truthfulness (Bingham 1999; Brown and Vidal 2013; Polaschek 2013). The case studies used to explore this question are drawn from the writings (novelistic, commentative and structured as conventional screenwriting) of Maya Deren and Marguerite Duras. The symmetry of their shared initials is pleasing, whilst their very different approaches to writing provide a broad enough perspective on autobiographical screenwriting that presages and pre-determines filmmaking. They are screenwriters and filmmakers of an intensely personal kind, their lives inextricable from the narratives they present to the world through the page and screen.

Through an interrogation of the autobiographical writing of first Maya Deren, and then Marguerite Duras, I will show that each has instigated screenwriting intended for, and mediated by, the filmmaking process, indicating some of the ideas that lie within the text, but which also lie metaphorically beyond the screen's surface. These ideas consist of significant formal images, narrative causal sequences, generalizations and ideal potentialities, which within screenwriting and the filmic realization of experience, depict and represent ideas of embodied sensation within autobiographical human events.

If it can be accepted that, in their differing ways, both Deren and Duras construct narratives of a more or less autobiographical kind, can further distinctions then be made between the nature of their transformations from literary and screenwriting texts to audio-visual text? The answer might lie in the ways by which each writer-filmmaker presents tactile sensation as a narrative element. For Deren, objects such as glass, knife and fabric are channels for communicating tactile sensation and haptic signification; for Duras, flesh and hair have similar significance. Therefore, something that unites both artists is in the process of transposition, if not sublimation, within the filmic realization of images contained in the screenwriting they each create.

If screenwriting can be regarded as somehow fundamental, original and an authentic model for narrative, what would be the point of replicating and further mediating such a mode of discourse through film? The ambiguous nature of the film's relationship to truth, be it fiction or documentary, is well recognized and merely condenses the essence of the screenwriting on which it is based. As Mecke relates, 'utopian discourse is, on the one hand, a literary 
1. genre with an author, an editor, and a fictional narrator, but, on the other

2. hand, it pretends to be or can be used as, an instruction for the creation of a

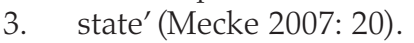

In the screenwriting of Deren and Duras, we are offered examples of their attempts to present utopian discourses in the form of some sort of autobiographical, written progenitor. However, in the translation of the written text to screen representation, there occurs an inevitable diminution of whatever authenticity was contained in the words that inspired their subsequent cinematic mediations. By focusing an analytical lens on how sensation and the senses are embodied in their work, I contend that we might begin to arrive at deeper truths about how linguistic codification serves to obscure or reveal some level of personal truth in their screenwriting and film work.

\section{MAYA DEREN: FILMING THOUGHT}

Perhaps somewhat perversely, I begin the first analysis by looking at a film that was apparently made without a script of a recognizable sort. In effect, therefore, I will work backwards from the screen image to discuss issues of written texts that are in some way related. Meshes of the Afternoon (Deren and Hammid, 1943) is a collaboration between Maya Deren and her first husband, Alexander Hammid, a Czechoslovakian photographer and film director, and filmed in their home in Los Angeles. It is believed that Hammid was in charge of the camerawork and the cinematography, while Deren worked on constructing the narrative and diegesis of the story. However, Tino Hammid, Alexander's son, has talked about a more evenly shared collaboration between the two authors:

There is not a clear distinction between the themes in Meshes and its shooting and editing. My father worked almost his entire career without film scripts [...] [he] treated the creative process in a very open and collaborative manner.

(Hammid 2012: n.pag.)

In its original 1943 version, the film contains no sound, and no written script as such seems to have survived. In the later version of 1952, non-diegetic music was added by Teiji Ito, Maya's third husband. For this article, however, I concentrate my attention on the original, silent version of the film.

Arguments persist that Meshes originates from something other than a formal screenplay. 'They played in the film themselves. There was no script. They worked out the overall outline together and talked over the shooting details while making the film' (Sitney 2002: 7). If true, such reports tend to support the view that Deren and Hammid collaborated on the film's structure and execution, whilst detailed planning or making a pre-existing blueprint, written or otherwise, may not have been carried out. Such a procedural, possibly improvisational, working method requires some description of the plot to aid our understanding of its autobiographical elements. Briefly, the action in Meshes proceeds as follows.

\section{MESHES OF THE AFTERNOON: NARRATIVE EXPOSITION}

In an early image of the film, a mannequin's arm comes into frame and leaves a paper flower on a road, presenting an initial contradiction for the audience. 
Both of these objects represent something alive (a physical human body and 1 . an organic flower), but each is completely inert, images of dead objects stand- 2 . ing in for their real counterparts.

Mysteriously, magically, a woman (Deren) appears to make the arm disap- 4 . pear, disrupting any strict adherence to realism that might have been intro- 5 . duced. The woman then ascends a flight of stairs, to sit with the flower on her 6 . lap, sensually touching her body.

We next see an extreme close-up of her eye. We are led to assume this 8 . as the woman (Deren) is the only person we have seen, thus far. This image 9 . reminds us of similar images from the history of surrealist cinema, most nota- 10. bly the scene of a woman's eye apparently being cut with a razor in Un Chien 11. Andalou (Bunuel 1929).

In the subsequent camera move, the eye forms a kind of symbolic tunnel 13 along which the viewer is permitted to leave the interior room to enter the 14 . exterior world of the film's other main protagonist: Deren herself in the guise 15. of a cloaked and hooded figure.

Following an edit, the cloaked figure (who may be construed as 'Death') makes an initial appearance and leaves a flower on a bed, replacing a knife that had previously taken up the same position. Seeing the figure of Death disappear, Deren transforms into an inanimate object, like a statue. She stares at the knife, doubtful, and her puzzlement urges us to ask whether it is the presence (rather than absence) of masculinity that makes her an object. and Death and instigate the appearance/disappearance of other surrealist 25. images of a key and a telephone out of its cradle, requiring to be replaced. We 26 . repeatedly see her as an active protagonist, animatedly or dizzyingly climbing 27. stairs, and resting in an armchair or on a bed. As she lays on the bed, a man 28. (Hammid) starts to touch her body sexually, and feminine desires are trans- 29. posed to masculine's when the flower metaphorically and filmically transforms 30 . into the knife.

As Deren and her flower once more take up their place on the bed, the 32 . figure of Hammid begins to loom over her. This initiates a further transfor- 33. mation of the flower into the knife, concretizing Deren's anxiety about her 34. husband's intentions. Suddenly throwing the knife at him, Hammid's image is 35. shattered into pieces of a mirror, past which we see the ocean and fragments 36. of broken mirror falling into the water. Hammid's face, and the inference of 37. him as a figure of threatening masculinity, likewise shatters and disappears. 38. Deren is liberated and the house, the woman's prison as we might construe 39. it, is opened to the sea: a symbol of limitlessness, cleansing infinity, but with a 40 . natural absence of constraining, man-made walls.

The breaking of the mirror also serves as a metaphorical reprise of the well-established idea that avant-garde filmmaking's antithesis to Hollywood cinema has often provoked a fragmentary, if not also iconoclastic, disruption of traditional narrative structures (Mulvey 2004; Arthur 2005). This reading of Meshes signals Deren and Hammid's early break with conventional cinematic narrative to forge a profoundly experimental, yet coherently expressive, film form that Deren would not replicate in her later work.

In a return to a form of reality, Hammid turns the key in its lock, re-enters the house and we realize with him what Deren has done to liberate herself. Covered with seaweed and shards of broken mirror, the now lifeless body 
1. of Deren is an autobiographical statement that her will was too strong to be 2. repressed.

3.

4.

5.

6.

\section{MESHES OF THE AFTERNOON: EMBODIED AUTOBIOGRAPHY}

In the narrative of Meshes, which is expressive of a cyclical flow of imagery but also features irrational juxtapositions of objects, images representing tactility and sensuality are tied up with the audience's desires and needs for information about the identity of the film's protagonist. The woman could be anyone, but she happens to be Maya Deren - the person responsible for constructing the narrative we are witnessing. As Vivian Sobchack puts it, in our striving to understand Deren's predicament 'objectivity and subjectivity lose their presumed clarity', wherein we as the film's spectators engage in 'a carnal interest and investment in being both "here" and "there", in being able both to sense and to be sensible, to be both the subject and the object of desire' (Sobchack 2004: 66). Alternatively, as expressed in the words of the psychologist Vittorio Gallese:

the meeting between viewer and thing implies intersubjectivity [...] it is a personal, not impersonal act [...] Empathy can be conceived of as the consequence of our natural tendency to experience interpersonal relations first and foremost at the implicit level of intercorporeality.

(Gallese 2016: 45)

The images of embodiment in Meshes signify an invitation to empathize with the sensuality of the woman's (Deren's) experience, the body and senses always involved in lived experience. 'Thrown into a meaningful lifeworld, the lived body is always already engaged in a communication and transubstantiation of the cooperative meaning-making capacity of its senses' (Sobchack 2004: 60-61). Being primarily a silent film, Meshes relies on visuality for its meaning creation. Sobchack extrapolates this to talk of Merleau-Ponty's 'insistence on vision as embodied and therefore constituted as part of, rather than against, the flesh and field of visuality that is the world' (Sobchack 2004: 101). With its repeated motifs of touching, hapticity and images involving tactile sensation, Meshes represents and expresses tactility through filmic images. These are images that reach beyond linguistic description, appealing to empathy with another form of physical experience, hinting at the expression of filmic truth not present in any pre-existing act of screenwriting.

However, such ideas of embodiment would remain abstract if they did not have some significance for the film's audience. It is part of the human condition to search for patterns, order and truth. With no pre-filmic script by which to assess Meshes' adherence to some form of veracity in its representations, it seems inevitable that we should engage in a certain amount of post-rationalization of what Deren intends us to understand. However, this should not prevent our attempt to identify whether or where veracity can be found. Perhaps there is never a bad time to reconsider notions of truthfulness (Ettema 2009). In life as in art, truth slips in and out of focus, receding and yet also seeming to be present, immediate and an apposite consideration in relation to autobiographical screenwriting and filmmaking. Illusive and often indeterminate, truthfulness seems to be at once declared and obscured. The 'seductive veracity' of the film (Banks 1990), which actually or intends to 
present the human form, persists in its mediating influence and contributes to 1 . the high regard in which Meshes continues to be viewed.

The particular ways by which the human form is represented demand 3 . further scrutiny. As Dairmuid Costello says, 'What embodiment does to 4. meaning is render meaning sufficiently opaque to engage, and then sustain, 5. our interpretive interest in the first place' (Costello 2007: 88). Here Costello 6. emphasizes an element of meaning creation that goes beyond the mere trans- 7 . action of interpretation. As he goes on to explain, 'Such "opacity" [...] is a 8 . consequence of the distinctive causal conditions operative in the creation of 9 . works of art' (Costello 2007: 88, original emphasis).

Costello's analysis inexorably suggests that meaning tends to go beyond 11 . whatever Deren might have predetermined or intended. In the present context, 12. this includes whatever form of a screenplay or written plan that might have 13 . existed prior to filmmaking. Deren, in particular, uses the possibility for works 14. of art to embody extended meanings, raising the possibility of not one, but 15 . several meanings to be held by several people, and subsequently contained 16 . within a single film.

Thus, whilst remaining if not obscure then at least narratively oblique, the 18 . line of reasoning that Meshes establishes (in the absence of a written text) 19. is one of the human body that instigates sensation, which motivates empathy, 20. that in turn creates identity. Following this logic, assessment of Meshes' auto- 21. biographical potential as a meaningful text reveals its power to represent the 22 . sense of touch, first through the empathetic moving image and, secondly, 23. through whatever supplementary writing Deren is able to provide. The reason 24 . why ideas of the body are particularly important in Meshes is that, as Laura 25. Marks says, 'film is grasped not solely by an intellectual act but by the complex 26 . perception of the body as a whole' (Marks 2000: 145).

More generally, our knowledge of the existence of the other's body is 28 . perceived as part of our fuller knowledge about, and experience of, the world 29. with ourselves within it, and not merely an exoticization of the body. Similarly, 30. Sartre ruminates on the existential need or desire to be connected, body to 31 . body, with the other, when he says 'I feel myself touched by the Other in my 32. factual existence; it is my being-there-for-others for which I am responsible. 33. This being-there is precisely the body' (Sartre 2001: 327, original emphasis). 34.

Notwithstanding her somewhat limited theoretical writing on filmmaking 35. that I will come onto, Maya Deren was not solely an intellectual filmmaker. 36. Her main concern for Meshes involves communicating the sensation of tactile 37. experience through the film's narrative. Marks uses the term 'haptic visuality' 38. to describe just such phenomena, suggesting an amalgam of tactile sensations, 39. our learned perceptions of touching the surfaces of objects, and our inner-felt 40 . bodily apprehension of things, including moving images (Marks 2000: 162). 41.

Therefore, Meshes manifestly evokes the sense of touch, of what objects 42 . feel like to our bodies and of our perceptions of them through the actions of 43 . Deren. In this, we begin to see the autobiographical nature of Deren's inten- 44 . tions for her filmmaking. These ideas form a bridge from the image, through 45 . representation, back to concerns about narrative. Whilst Marks cautions 46. us that the haptic image forces the viewer to contemplate the image itself 47. instead of being pulled into narrative' (Marks 2000: 163). There is a clear privi- 48. leging of the image's surface. Spectatorial sensation infers the optical image 49. which'affords the illusion of completeness that lends itself to narrative' (Marks 50. 2000: 163). Maurice Blanchot asks similarly pertinent questions of when our 51. 
1. relationship with the image reaches beyond a fascination with the gaze that is

2. returned or not, and a reappraisal of desire for a melding of the senses when

3. touching the image is also to touch the subject:

4.

But what happens [...] when the matter of seeing is a sort of touch, when seeing is in contact at a distance? [...] What happens when what is seen imposes itself on your gaze, as though the gaze has been seized, touched, put in contact with appearance?

(Blanchot 1981: 75)

In the absence of traditional screenwriting, Meshes is a silent text, a filmic text that Deren post-rationalizes only in her later writing. What narrative there exists in Meshes is a filmed account of some aspects of Deren's personalized, tactilic and psychological experiences (through her husband) of assorted objects. The tactility we see and perceive in images of Deren's body, a flower, flesh and glass, is of pivotal importance in Meshes. Without conflating the narrative's exegesis with our own lived experience, we nonetheless cannot help but empathize with Deren's experience of events played out on screen. As Jennifer Barker ably summarizes '[w]e commit ourselves to the film's world without ever abandoning our own world, for the limits of our bodies are never forgotten or confused in the handshake. We know where "we" end and the other begins' (Barker 2009: 94).

In other words, Deren's images of embodiment in Meshes present, not merely the appearance of tactility, but initiate feelings of empathy between filmmaker/film subject and audience. We as the audience may be denied a truly physical connection to the things Deren touches in the film world she creates. What related writing by Deren that does exist is distinctly limited, imposing an additional mediating influence through language and making our comprehension of the film's obtuse narrative all the more difficult.

In the words of Michael Taussig (1992): ' $[\mathrm{t}]$ he connection with tactility is paramount, the optical dissolving, as it were, into touch and a certain thickness and density [...] mimesis implies both copy and substantial connection, both visual replication and material transfer' (Taussig 1992: 144-45). I would argue that the visual replication that Taussig refers to describes our perceived connections through the mind's eye with the filmmaker: our visual imagination, if you will, of images contained in the written text as well as the filmic narrative.

Drawing a few strands together, screenwriting is in a general sense intrinsic to inviting interpretations of its linguistically codified meanings. The writing of Deren in relation to Meshes resists simplistic interpretation, coming as it does after filmmaking was completed. Instead, the narrative in Meshes offers a level of opacity resistant to singular meaning creation. If, as is commonly accepted, original screenwriting for Meshes of the Afternoon cannot be identified (Sitney 2002: 7), we must look to Deren's other writing for clues to her preparatory work for the films that credit her as a writer.

In the following passage from An Anagram of Ideas on Art, Form and Film (Deren 1946), Jamie James (2017) offers a revealing critique of Deren's own account of writing the narration for Maeva: Portrait of a Tahitian Girl (Bonsignori 1961), with the music of Deren's last husband Teiji Ito providing the soundtrack: 
The most remarkable thing about the narration is simply the fact that 1 . that's what it is: Deren was an accomplished writer, but in her films 2. words are banished; the experience is entirely visual. 3.

(James 2017: 19) 4.

Whilst avoiding overt ethnographic elements, the film's subject and setting 6 . link it directly to Deren's earlier life in Haiti. The story's situations are perhaps 7. trite, but sensual and universal nonetheless, presenting an amalgam of the 8 . loss of virginity, jealousy, regret and resignation to one's fate viewed through 9 . the eyes of the protagonist. James' transcription of Deren's narration provides 10 . a lucid and persuasive picture of autobiographical intentionality: 11.

At home again, Maeva contemplates her reflection in the mirror 13. She loosens her pigtails and brushes out her long hair. 14. I was pretty. I'm sure I was pretty. But what was it that they saw, 15. that I could not see in the mirror? Something that made them 16. quiet, as if they were listening to something. Was it because of 17. their looking that I began to feel strange? The way the air feels 18. when a hurricane is on the way.

Post-rationalizing the screenwriter's art, Deren offers the following, self- 22. reflexive analysis of the writer's task: 23. The realist describes his experience of reality. He denies the value of the 25 . original, artificial reality created by the rigours and disciplines of the art 26 . instrument. But he is unwilling, also, to submit to the rigours and disci- 27. plines of the scientific instrument in objectively analysing the existent 28 . reality.

(Deren 1946: 12) 30

In this passage, Deren effectively distinguishes between her beliefs about our 32 . experience of reality and real experience. Moreover, she writes eloquently of 33 . the filmmaker's creative transposition into filmic form of ideas about that 34 . same reality and experience. 35.

Here I draw particular attention to what would become Deren's diver- 36. gence from the writing and filmmaking of the French Nouvelle Vague in the 37. 1940s and 1950s. Already, Deren appeared to champion the camera as both an 38 . instrument of creative artificiality and as a scientific instrument of objectivity. 39. Clearly, whatever transposition may occur between the formation of her ideas 40 . for a film (for which we have scant evidence of original screenwriting) and the 41 . filmed events, Deren's instruments for expressing (realizing) her reality were 42. not a typewriter and paper but a Bolex film camera and her own body. 43.

To return to a major question posed earlier, what truth we may discern in 44 . the eventual film Deren makes, has not been mediated through her screen- 45 . writing alone. Somewhat defensively perhaps in her theoretical writing, Deren 46. returns repeatedly to notions of truth, referring to a 'truth that is stranger 47. than fiction' (Deren 1946: 19). Continuing this confessional theme, she writes 48. that, '(t)aken in terms of the representation of the expression of natural real- 49. ity, the originality of achievement becomes, then, an originality of discovery, 50. a pursuit of the exotic, novel condition, exterior or interior, the search for the 51 . "truth which is stranger than fiction"' (Deren 1946: 22, original emphasis). 52. 
1. With this passage delineating the screenwriter's appearance through the filmic

2. medium, and Deren's discovery of a personal form of truth, I will now move 3. on to discuss the film-related writing of Marguerite Duras.

4.

5.

6.

\section{MARGUERITE DURAS: WRITING FILM}

In a highly wrought piece of writing, the synopsis to Duras' script for Alain Resnais' film Hiroshima Mon Amour (Resnais, 1959) furnishes the director with, amongst other supplementary guidance, a synopsis of the salient events that make up the plot of the film. At the beginning of the film we see two human bodies, unclearly at first, so that we cannot ascertain their exact relationship to each other. 'Instead we see the mutilated bodies - the head, the hips - moving - in the throes of lovemaking' (Duras 1966b: 9). These bodies are de-personalized, universal, bodily details of arms, torsos and heads, representing states of both life and death. As Duras writes in her instructions to Resnais: '[i]t is only by slow degrees that from these formless, anonymous bodies their own bodies emerge' (Duras 1966a: 9).

Duras' early use of physical description adds power to her account of what these appearances are intended to communicate to Resnais: '[t]hey are lying in a hotel room. Naked. Smooth bodies. Intact' (Duras 1966a: 9). The staccato, abrupt use of single-word sentences only increases the directness, almost violent descriptions of their physical appearance. In this passage, Duras establishes a direct connection with both the screenwriting for Hiroshima Mon Amour and the mise en scène of a similar scene in her novel The North China Lover (Duras 1992) which, as Haven (2014) argues, may or may not depict the real events of a transnational affair. Leaving aside its veracity for the moment, the scenario for Hiroshima Mon Amour, as Caroline Mohsen relates, is a multilayered narrative:

It is clear in Hiroshima mon amour that place is not only apprehended by the senses. It is also bound to the protagonists by affective ties, effectively joining time and space [...] inasmuch as it is by one's lived body that a person is 'here' or 'there'.

(Mohsen 1998: 570-71, original emphasis)

In her written prompts to Resnais, Duras shapes both the descriptive power of her screenwriting and guides Resnais' reading of the narrative's concerns with ideas about physical sensation.

The body is represented as a place at the very beginning of Hiroshima mon amour. The first scene of the film opens with the bodies of the two protagonists, whom we have not yet seen in their entirety (they are their bodies). These two bodies hold in them the entire story of the film we will be seeing.

(Mohsen 1998: 571)

Relating the dialogue she intends for the film, Duras has connected equally important things to say about the related subject of memory: 'SHE: (softly): Listen to me. Like you, I know what it is to forget. HE: No, you don't know what it is to forget' (Duras 1966a: 24, original emphases). In this exchange, Duras indicates through the man's dialogue that the woman is trying to forget, but is not able to completely. Such references to the various degrees 
of memory, its powers of truth, indeterminacy and duplicity, are returned to 1 . throughout the texts that make up the published book. As Duras writes, '[w]hy 2. deny the obvious necessity for memory?' (Duras 1966a: 24). Against such 3. admissions and claims, we see the inherent problematic of autobiographi- 4 . cal writing and its subsequent translation into dramatic screenwriting. When 5 . veracity is tied to memory, it is a tenuous, imprecise thing; a situation that 6 . does not improve during the filmmaking process.

In the first scene of the two lovers sharing a shower, a recurring motif is 8 . established of the cleansing action of water, washing away guilty memories of 9 . physical experience: 'SHE: Hands become useless in cellars. They scrape. They 10. rub the skin off [...] against the walls' (Duras 1966a: 34). In such exchanges, 11. Duras' characters confess to memories of sensation that appear more visceral, 12. immediately physical. Later, Duras has the woman, a surrogate for the autho- 13. rial voice, offer yet more judgements on her sensory experiences: 14.

As it was for him, oblivion will begin with your eyes. Just the same.

Then as it was for him, it will encompass your voice. 18.

Just the same.

Then, as it was for him, it will encompass you completely, little by little. 20.

You will become a song.

(Duras 1966a: 77) 22

In this passage from the published screenplay in book form, Duras invokes the 24 . senses to establish equivalence between the Japanese man and her (Riva's) 25. German lover. At this point in the film, the two men become merged, fused 26. together through Duras' depictions of sense images into the physical body 27. of a single lover. In an important appendix to the screenplay, titled Nocturnal 28. Notations, Duras appears to consider dialogue as insufficient to communicate 29. the sensuality of events on screen. Her account of the young woman's head 30. being shaved at Nevers, eventually naming her as Riva, is straightforwardly 31. descriptive of physical sensation. As Duras writes, '[w] hat happens then 32. between Riva and her mother is purely physical' (Duras 1966b: 95). Alternating 33. between two modes of dramatic fiction, the novel and screenwriting, Duras 34 . describes her first love in Nevers, encapsulating a central thesis through the 35 . character of Riva:

I couldn't see any difference at all now between his body and mine. All I could see was an extraordinary similarity between his body and mine. His body had become mine, I was no longer capable of distinguishing it. I had become the living denial of reason.

103) 42

(Duras 1966b: 103) 42

43.

In this admission, Duras lays bare her autobiographical connection with Riva, 44 . her re-constituted experience of first love and the physical sensations conjured 45 . up by its memory.

In her screenwriting for Une Aussi Longue Absence (1966b), Duras writes as she would a novel (or at least a story). It is a piece of prose in note form, a stream of ideas, intentions, pointers and directions for a potential director. Most notably in the pursuit scenes, the absence of dialogue urges a particular writing style, with long descriptive passages of the physical movements 
1. through spaces and locations of each character (set directions if you will) only

2. intermittently punctuated by dialogic elements.

In her descriptions of the Tramp's physical appearance, as she circles around him, following his actions and seeking confirmation of his true identity, Duras homes in on his physical details. In these scenes, it is the character Thérèse this time who stands in for Duras, observing, describing the shape and physicality of the man as she, Thérèse, pursues him through the early morning streets of Paris. The kind of sensation that Duras, through Thérèse, is writing about in Une Aussi Longue Absence describes something in addition to the usual five senses: the sensation of memory or the physical description of remembering how things felt and appeared. Duras further emphasizes the embodied nature of sensation in the passage where they are dancing in the café:

Very gradually, Thérèse begins to stroke his head; discreetly, but also because she's incapable of preventing herself. She goes on doing it. And then her hand comes across a large, vertical scar on his head. She becomes rigid. [...] Thérèse sees the scar in the mirror. He's a man with a hole in his head. Like a bombed house, still standing, but damaged beyond repair. And yet he gives the perfect impression of existing.

(Duras 1966b: 176)

In this and the following passage, Duras effectively combines more than one sense such as hearing and seeing, but also touching, with that of memory:

There is silence in the room. The only sound to be heard is that of this man being given his meal by his wife - being given his innocent meal by his wife who is 'guilty' of memory.

(Duras 1966b: 176)

The guilt of memory, or the memory of guilt, is an idea that permeates Duras' writing. Resonating with the filmmaking of Deren, Duras writes in a profoundly autobiographical, confessional manner, drawing on her personal history so that we are unable to differentiate between lived experience and imagination. As Catherine Sousslof elegantly sums up, '[t] he successful chaining together of the images in Deren's films relies on her use of herself in her films, a method that creates a logic' (Soussloff, 2001: 118). It should be recognized that in the writing of a text, or the filming a portrait of a head and shoulders or some other part of a body, the filmmaker incorporates aspects of self-portraiture and self-expression, becoming a character or subject within their own film, something I have elsewhere called 'the fictivization of a personal narrative' (Wilson 2014: 75, original emphasis).

\section{CONCLUSIONS}

Jutta Brückner and Jeanette Clausen (1995) trace two lines of approach to autobiography: a semiotic one in which the daughter separates from the body of the mother, and a symbolic one that concentrates on the language and culture defining the autobiographical line of the father. It seems entirely plausible to conclude that Duras' screenwriting and novelistic writing, which offers a re-telling of sexualized rebelion against her mother's careful parenting, observes the semiotic approach; whilst Deren, before her, adopts a version 
of the symbolic one in which proto-feminist avant garde expression strives to 1 . wrest the female body back from controlling masculinity.

This article situates Deren and Duras in a primarily pre-feminist, pre- 3 . gaze-theory milieu (Mulvey 1975). Their stories are, therefore, shaped by their 4 . contemporary circumstances, circumscribing the expected place of women 5 . (female artists included) in the world of literature, screenwriting and cinematic 6. arts. In their creative outputs that evidence individual visions of autobiograph- 7 . ical works, Deren and Duras fall into a somewhat rarefied category of women 8 . artists who bring their vision of female experience and the female body to the 9 . page and screen. The films that emanate from the screenwriting of both Deren 10 . and Duras counter male-centric traditions of cinematic representation. This is 11 . screenwriting wherein the female spectator is steered into viewing representa- 12 . tions of female experiences of narrative in a secondary way - by identification 13. with a male spectator. Pre-feminist they may be, yet in their different ways and 14 . to greater or lesser degrees, the resulting films depict female lives and experi- 15 . ences in a manner that is also pre-male gaze (Kordela 2009). Duras openly 16. presents a narrative that centres on a sexualized young woman, a life narrative 17. that is circumscribed, selected and which recognizes its appeal to the male 18. gaze. Its candour and narrativized honesty are, in large part, its strength. We 19. might say that Duras writes a filmed narrative of experience, whereas Deren 20. films and then writes about how she expresses a number of ideas.

An inherent problematic is introduced in rationalizing historical screen- 22 . writing through a solely feminist or even modernist lens. However, this should 23. not negate the validity of such works as records of female experience and the 24 . writers as both the subjects and makers of narratives (Mulvey 2004). Through 25. the time travel enabled by the filmed representations of Deren's and Duras' 26. screenwriting, they relate historical experience through the immediacy of the 27. word. More importantly in the present context, contemporary readings of the 28 . originating texts at the heart of Meshes of the Afternoon and The Lover necessar- 29. ily lean towards'a general shift away from gaze theory in feminist film studies', 30. for the obvious reason that it 'cannot adequately account for the enjoyment a 31. woman might take from' viewing a film in which they are the central charac- 32 . ter (Polaschek 2013: 15). We should now ask what this reveals of the notion 33. of truth that was introduced earlier. What of written fiction's suitability for 34 . expressing aspects of lived experience that can go on to form screenwriting 35 . that shapes cinema's self-reflexive presentation of lived experience? 36.

Is it not then the function of fiction to wrest the conditions for totalization from their concealment? Even more so, is it not stated that these conditions stem less from transcendental possibility than from existential making-possible? What mode of discourse is better suited to articulate this making-possible than the mode that plays on the imaginative variations of a fictive experience?

(Ricoeur 1988: 140)

As evidenced in the various writings of Deren and Duras, and in the films 46. their writing instigates, the phenomenology of real events requires, demands, 47. the incorporation of fictional narratives for truthfulness to emerge. Reflecting 48. the thinking of Heidegger, Ricoeur views the role of repetition as pivotal in 49 . reinforcing the combinatory power of what he terms 'phenomenology's quest 50 . for authenticity and fiction's exploration of the paths for making this authen- 51 . ticity possible' (Ricoeur 1988: 140-41). 
Digging a little deeper into the veracity of what Deren and Duras offer as life stories, what do we make of their connections to truthfulness and authenticity? Even if Duras dramatized a remembered account of her affair with the man in French Indochina, it does not follow that the narrative, mediated through screenwriting and the filmmaking process, can be regarded as a lie. Therefore, it must be critiqued otherwise. As Mecke reminds us, 'the opposite of lying cannot merely be truth, but is necessarily a linguistic and social practice' (Mecke 2007: 8). In sharing their accounts of life events - one an external expression of internalized anxieties about love and death, and the other a somewhat idealized recreation of a formative sexual relationship both writer/filmmakers play somewhat fast and loose with truth. It is as if the many processes of mediation that each project went through before reaching an audience have decimated any essential truth they may have contained.

In the fictional worlds created in the filmmaking-writing of Deren (the repetition of embodied images), and in the personal narratives in the writing-filmmaking of Duras (of tactile sensation), each describe different but complimentary aspects of truth, which are not harnessed irrevocably to the constraining impulse of realism. For Deren, the artwork is the film of Meshes of the Afternoon, whereas for Duras it is the written text itself. In the former, the image of the mirror is also an image of Deren the film's subject. In the latter,

1. The Lover is a series of images that represent what autobiographical truths the screenwriting may or may not contain. For both writers, therefore, the reproduction of phenomenological truth requires the structure of a fictional narrative for its authenticity.

\section{REFERENCES}

Annaud, Jean-Jacques (1992), The Lover, France, UK and Vietnam: Films A2. Arthur, Paul (2005), Line of Sight: American Avant-garde Film Since 1965, Minneapolis, MN: University of Minnesota Press.

Banks, Marcus (1990), 'The seductive veracity of ethnographic film', Visual Anthropology Review, 6:1, pp. 16-21.

Barker, Jennifer M. (2009), The Tactile Eye: Touch and the Cinematic Experience, Berkeley, CA: University of California Press.

Bingham, Dennis (1999), "I do want to live!": Female voices, male discourse, and Hollywood biopics', Cinema Journal, 38:3, pp. 3-26.

Blanchot, Maurice (1981) The Gaze of Orpheus (ed. P. Adams Sitney, trans. L. Davis), Barrytown, NY: Station Hill.

Bonsignori, Umberto (1961), Maeva: Portrait of a Tahitian Girl, USA: Cascade Films.

Brown, Tom and Vidal, Belén (eds) (2013), The Biopic in Contemporary Film Culture, New York: Routledge.

Brückner, Jutta and Clausen, Jeanette (1995), 'On autobiographical filmmaking', in J. Brückner and J. Clausen (eds), Women in German Yearbook, vol. 11, Lincoln, NE: University of Nebraska Press, pp. 1-12.

Buñuel, Luis (1929), Un Chien Andalou, France: Ursulines Film Studio.

Costello, Dairmuid (2007), 'Whatever happened to "embodiment"? The eclipse of materiality in Danto's ontology of art', Angelaki: Journal of the Theoretical Humanities, 12:2, pp. 83-94.

Davies, Rosamund (2010), 'Screenwriting strategies in Marguerite Duras's script for Hiroshima, Mon Amour (1960)', Journal of Screenwriting, 1:1, pp. 149-73. 
Deren, Maya and Hamid, Alexander (1943), Meshes of the Afternoon, USA: 1. Public Domain. 2.

Deren, Maya (1946), An Anagram of Ideas on Art, Form and Film, New York: The 3. Alicat Book Shop Press. (2004), 'Cinematography: The creative use of reality', in L. Braudy and 5. M. Cohen (eds), Film Theory and Criticism, 6th ed., New York and Oxford: 6. Oxford University Press, pp. 187-98.

Duras, Marguerite (1966a), Hiroshima Mon Amour (trans. R. Seaver), screen- 8. play, London: Calder and Boyars. - (1966b), Une Aussi Longue Absence (trans. B. Wright), London: Calder 10. and Boyars.

(1992), The North China Lover (trans. L. Hafrey), New York: The New 12. Press. (1)

$$
\text { . }
$$
8. 9.

Ettema, James S. (2009), 'The moment of truthiness: The right time to consi- 14. der the meaning of truthfulness', in B. Zelizer (ed.), The Changing Faces of 15. Journalism: Tabloidization, Technology and Truthiness, New York: Routledge, 16. pp. 114-26. 17.

Gallese, Vittorio (2016), 'Visions of the body: Embodied simulation and aesthe- 18. tic experience', Humanities Futures, https://humanitiesfutures.org/papers/ 19. visions-body-embodied-simulation-aesthetic-experience/. Accessed 120. November 2017.

Hammid, Tino (2012), 'Images and themes in Meshes of the Afternoon', email 22. interview with Jaime Costas Nicolás, https://www.academia.edu/6817442/ 23. Images_and_themes_in_Meshes_of_the_Afternoon. Accessed 12 August 24. 2017.

Haven, Cynthia (2014), 'Marguerite Duras's The Lover: But, but, but ... did it 26. really happen?', The Book Haven, http://bookhaven.stanford.edu/2014/05/ 27. marguerite-durass-the-lover-but-but-but-did-it-really-happen/. Accessed 28. 10 August 2017.

James, Jamie (2017), 'Maya Deren's last script', The Yale Review, 105:1, pp. 30. 14-31, http://onlinelibrary.wiley.com/doi/10.1111/yrev.13163/epdf. 31. Accessed 14 August 2017.

Kordela, A. Kiarina (2009), 'The gaze of biocinema', in T. Trifonova (ed.), 33. European Film Theory, New York and London: Routledge, pp. 151-64. 34.

Marks, Laura (2000), The Skin of the Film: Intercultural Cinema, Embodiment and 35. the Senses, Durham, NC and London: Duke University Press. 36.

Mecke, Jochen (ed.) (2007), Cultures of Lying: Theories and Practice of Lying in 37. Society, Literature and Film, Berlin and Cambridge, MA: Galda and Wilch 38. Verlag. 39.

Mohsen, Caroline (1998), 'Place, memory, and subjectivity, in Marguerite 40. Duras' Hiroshima mon amour', Romantic Review, 89:4, pp. 567-83. 41.

Mulvey, Laura (1975), 'Visual pleasure and narrative cinema', Screen, 16:3, pp. 42. 6-18. 43.

(2004), 'Looking at the past from the present: Rethinking feminist film 44. theory of the 1970s', Signs: Journal of Women in Culture and Society, 30:1, pp. 45. 1286-92.

46.

Polaschek, Bronwyn (2013), The Postfeminist Biopic: Narrating the Lives of Plath, 47. Kahlo, Woolf and Austen, Basingstoke and Hampshire: Palgrave Macmillan. 48.

Resnais, Alan (1959), Hiroshima Mon Amour, France and Japan: Argos Films. 49.

Ricoeur, Paul (1988), Time \& Narrative, Vol. 3: Narrated Time, Chicago and 50. London: University of Chicago Press. 51. 
1. Sartre, Jean-Paul (2001), Jean-Paul Sartre: Basic Writings (ed. S. Priest), London:

2. Routledge.

3. Sitney, P. Adams (2002), Visionary Film: The American Avant-Garde, 1943-2000,

4. 3rd ed., New York: Oxford University Press.

5. Sobchack, Vivian (2004), Carnal Thoughts: Embodiment and the Moving Image,

6. London and Los Angeles, CA: University of California Press.

7. Soussloff, Catherine M. (2001), 'Maya Deren herself', in B. Nichols (ed.), Maya

8. Deren and the American Avant-Garde, Berkeley, CA and London: University

9. of California Press, pp. 105-29.

10. Taussig, Michael (1992), The Nervous System, New York: Routledge.

11. Wilson, Gavin (2014), 'Cell/ular cinema: Individuated production, public

12. sharing and mobile phone film exhibition', Ph.D. thesis, Leeds: University

13. of Leeds.

14.

16.

\section{SUGGESTED CITATION}

Wilson, Gavin (2020), 'Negotiating autobiographical truth: Embodying sensation in the narrative screenplay', Journal of Screenwriting, 11:1, pp. 99-113, doi: https://doi.org/10.1386/josc_00015_1

\section{CONTRIBUTOR DETAILS}

In his early career, Gavin Wilson worked as a freelance camera technician and occasionally as a director in the UK film and television industry. Later he was a sector manager for Screen Yorkshire, one of the United Kingdom's regional screen media development agencies. His doctoral research onwards (Ph.D.,

6. University of Leeds) involves fieldwork at a number of international film festivals, whilst his published work spans film-philosophy, filmmaking as research

28. and film festival studies. He has served as a judge at several international film

29. festivals and is currently an assistant professor at Gulf University, Kuwait.

30. \& Sciences, Gulf University for Science \& Technology, Block 5, Building 1, Mubarak Al-Abdullah Area/West Mishref, Kuwait.

E-mail: Wilson.G@gust.edu.kw

(D) https://orcid.org/0000-0003-3289-8911

Gavin Wilson has asserted their right under the Copyright, Designs and Patents Act, 1988, to be identified as the author of this work in the format that was submitted to Intellect Ltd. 